\title{
Изменение теплоты сгорания древесных пеллет в зависимости от степени их торрефикации
}

\author{
Ю. А. Геллер ${ }^{1, *}$, Е. О. Ходяшов ${ }^{2}$ \\ ${ }^{1}$ Национальный исследовательский университет "МЭИ", Москва, Россия \\ ${ }^{2}$ Российский государственный университет им. А.Н. Косыгина \\ (Технологии. Дизайн. Искусство), Москва, Россия
}

\begin{abstract}
Аннотация
Для улучшения физико-химических свойств древесных пеллет, например, увеличения насыпной плотности, повышения теплоты сгорания, снижения гигроскопичности применяется торрефикация - процесс медленного нагрева (не более $50^{\circ} \mathrm{C} /$ мин.) древесины в инертной среде при температуре до $300^{\circ} \mathrm{C}$.

В работе проведено сравнение характеристик торрефицированных и неподвергшихся термической обработке древесных пеллет. Представлены результаты эксперимента по потере массы образца, выходу летучих, изменению температуры образца в процессе разложения образца древесной биомассы. Эксперимент проводился на термоанализаторе SDT Q600 с программным обеспечением Universal Analisys 2000.

В процессе эксперимента пеллеты сперва нагревались до $103^{\circ} \mathrm{C}$ в течение 15 минут, что сопровождалось удалением влаги, затем с нагревом до $800^{\circ} \mathrm{C}$ происходило термическое разложение образца с выделением летучих органических веществ. В результате обработки данных получены значения теплоты сгорания неторрефицированных ( 19 МДж/кг) и (от 21 до 24 МДж/кг) торрефицированных пеллет.
\end{abstract}

\section{Ключевые слова}

Торрефикация древесных пеллет, теплота сгорания, возобновляемые углеводородные ресурсы

\section{Введение}

Россия располагает свыше $25 \%$ мировых запасов леса, занимается активной переработкой древесного материала, поэтому использование древесной биомассы становится достаточно актуальным. Биомасса используется как возобновляемый источник при выработке энергии.

Увеличение насыпной плотности, снижение технологической влажности и повышение теплового потенциала древесного топлива, можно добиться способом торрефикации, заключающимся в медленном нагреве (скорость нагрева не более $50{ }^{\circ} \mathrm{C} /$ мин.) древесины в инертной среде при температуре $250-300{ }^{\circ} \mathrm{C}$. В результате процесса термического преобразования древесины, в том числе мягких древесных отходов, получается твердый однородный гидрофобный биологически стойкий продукт $[1,2]$

В процессе торрефикации биомасса приобретает новые характеристики, которые, несомненно, увеличивают КПД использования топлива. В процессе торрефикации возникает экзотермическая 
реакция, которая требует особого изучения, поскольку непосредственно влияет на успех торрефикации, косвенно на полезное использование топлива в газопоршневых установках, которые используются в некоторых схемах для активации процесса в целом [3].

Сырьем для производства торрефицированных пеллет служат отходы деревообработки, растениеводства, а также биомасса из специально выращенных энергетических культур. Теплотворная способность 1 т торрефицированной древесной биомассы составляет $5-5,2$ Гкал, а изготовленные из этой биомассы гранулы не боятся влаги. Древесная биомасса состоит из трех основных полимерных структур: целлюлозы $(45-55 \%)$, гемицеллюлозы $(24-$ $30 \%)$ и лигнина (20-29\%). Лигнин в биомассе - основной связующий элемент. Более высокое содержание лигнина улучшает связывание материала и условия прессования.

В процессе торрефикации из древесины извлекается влага, а также летучие вещества, образующиеся в ходе распада гемицеллюлозы и частичного разложения целлюлозы и лигнина. Так как из лигнина и целлюлозы происходит выделение лишь небольшого количества летучих компонентов, торрефицированная древесина сохраняет большую часть своей энергии. Во время торрефикации происходит значительная потеря массы материала (до 20-30\%), происходит уплотнение энергии потенциального древесного топлива $[4,5]$. В результате получается более пористая биомасса с меньшей объемной плотностью, что позволяет значительно снизить энергетические затраты при пеллетизации по сравнению с процессом получения «обычных» древесных пеллет. Содержание лигнина и жирных насыщенных структур в торрефицированной древесной биомассе позволяет получить гранулы с высокой насыпной плотностью - 750-850 кг $/ \mathrm{m}^{3}$.

Отличия торрефицированных пеллет от обычных:

- лучшая энергоемкость, по сравнению с обычными пеллетами, низшая теплота сгорания торрефиката составляет 20-23 мДж/кг;

- не подвержены биологическим процессам гниения;

- устойчивы к поглощению влаги, не требуют специальных условий хранения;

- нет жестких требований к размеру, качеству и влажности древесного сырья

- Промышленное производство торрефицированных пеллет сдерживает несколько факторов:

- При некорректном управлении процессом и несовершенной технологии легко перейти из стадии торрефикации в стадию глубокого пиролиза. Если выход торрефиката составляет $60-70 \%$, то неточное управление процессом приведет к падению выхода вдвое. Поэтому температурный режим на установках для торрефикации надо выдерживать намного строже, чем при углежжении.

- Требуется автоматизированное управление процессом и использование иных источников теплоносителя.

- При всех своих преимуществах процесс торрефикации древесины является дополнительной операцией для производства гранул, требующей дополнительной энергии, и ведет к удорожанию конечного продукта.

- Разные размеры частиц древесины и их различная влажность могут привести к неравномерной карбонизации древесины, так как теплопередача будет неравномерна. Самые мелкие фракции превратятся в уголь, в то время как крупные еще не будут полностью подвержены торрефикации. 
Материалы и методы решения задач, принятые допущения

Для подробного изучения процессов, происходящих во время торрефикации и сгорания торрефицированных пеллет был использован Термоанализатор SDT Q600. Этот прибор позволяет одновременно проводить дифференциальный сканирующий калориметрический (ДСК) и термогравиметрический (ТГ) анализ. Термоанализатор измеряет тепловой поток и изменение массы, сопровождающие энергетические переходы и реакции в материалах в диапазоне температур до $1500^{\circ} \mathrm{C}$. Полученная информация позволяет отличить эндотермические и экзотермические процессы, не сопровождающиеся изменением массы (например, плавление и кристаллизацию), от тех процессов, которые проходят с изменением массы (например, термическое разложение образца). Одновременное проведение калориметрического и термогравиметрического анализа одного и того же образца обеспечивает высокую точность анализа и позволяет существенно снизить экспериментальную погрешность.

Вместе с устройством управления и соответствующим программным обеспечением Universal Analisys 2000 термоанализатор SDT Q600 образует систему для термического анализа $[8,9]$.

В качестве устройства управления выступает компьютер, который выполняет следующие функции:

- Обеспечивает связь между пользователем и аналитическим оборудованием;

- Позволяет пользователю задать условия эксперимента (конечная температура, темп нагрева) и ввести значения констант;

- Сохраняет экспериментальные данные;

- Запускает программы для анализа данных.
Измерительная часть термоанализатора SDT Q600 состоит из трех основных деталей:

- аналитические весы, имеющие два луча (для измеряемого образца и образца сравнения), снабженных термопарами и обеспечивающие измерение теплового потока и массы;

- печь, с контролируемой газовой средой атмосферы и температурой образца;

- кожух, в который заключены все электронные и механические детали прибора.

Для эксперимента были использованы 4 образца пеллетизированной древесины: 1 - исходный, 3 - образца древесины, прошедшие торрефикацию.

Для экспериментов на Q600 используются платиновые (40 и 110 мкл) и керамические тигли (40 и 90 мкл). Платиновые тигли рекомендуются для работы при температуре $1000^{\circ} \mathrm{C}$, а также из-за их общей инертности и простоты очистки. Керамические тигли рекомендуются для работы при температуре $1500^{\circ} \mathrm{C}$, а также для образцов, которые реагируют с платиной.

После тарировки весов с пустыми тиглями образец измельчался до соответствующего размера и помещался в очищенный тигель (в проведённых мной экспериментах использовался керамический тигель).

После этого с помощью программного обеспечения прибора оба тигля автоматически закрывались в герметичной камере печи.

Эксперимент начинается с непрерывной продувки рабочим газом (в данном случае - атмосферным воздухом, 100 мл/мин.), после установления равновесия лучей весов с тиглями запускается нагрев.

Процесс нагрева идет в несколько этапов. Первый — процесс сушки с 
температурой до $103^{\circ} \mathrm{C}$ в течение 15 минут, второй - термическое разложение образца - с нагревом до $800^{\circ} \mathrm{C}$. Во время второго этапа происходит выделение летучих органических веществ и остаётся угольный остаток. Поскольку эксперименты проводились в атмосфере воздуха, то одновременно происходило окисление как летучих продуктов, так твердого остатка. Интенсивность процесса изменялась с изменением температуры.

После достижения заданной температуры образец под действием непрерывной продувки воздухом охлаждается до $30{ }^{\circ} \mathrm{C}$. Затем происходит остановка работы прибора, извлекается тигель, удаляются остатки образца. Весь эксперимент может занимать от 1.5 до 2.5 часов.

\section{Результаты}

Один из таких экспериментов, полученный в программе Universal Analisys 2000, для примера приведён на рисунке 1. Остальные данные приведены в таблице 1.

Здесь показано несколько кривых: кривая (1) отвечает за изменение веса с течением времени, кривая (2) отвечает за изменение производной по весу от времени, линия (3) показывает изменение температуры в процессе нагрева, кривая (4) - величину теплового потока к образцу и впоследствии при экзотермической реакции от образца в инертную среду, линия (5) является касательной к (4).

На графике хорошо заметна полочка линии (1) в начале процесса нагрева, точно такая же полочка есть у кривой (3), которая показывает, что данный процесс сушки проходит изотермически при $103^{\circ} \mathrm{C}$. Можно мысленно провести горизонтальную прямую влево от крайней точки зелёной полки на графике и получить значение в 94\%, что показывает остаток массы образца после испарения влаги, значит изначально в образце содержалось $6 \%$ влаги.

Далее программой задано повышение температуры процесса: кривая (3) устремляется в правый верхний угол, а на кривой (2) теперь отчётливо виден первый пик, что говорит о процессе выхода летучих, потери массы образца.

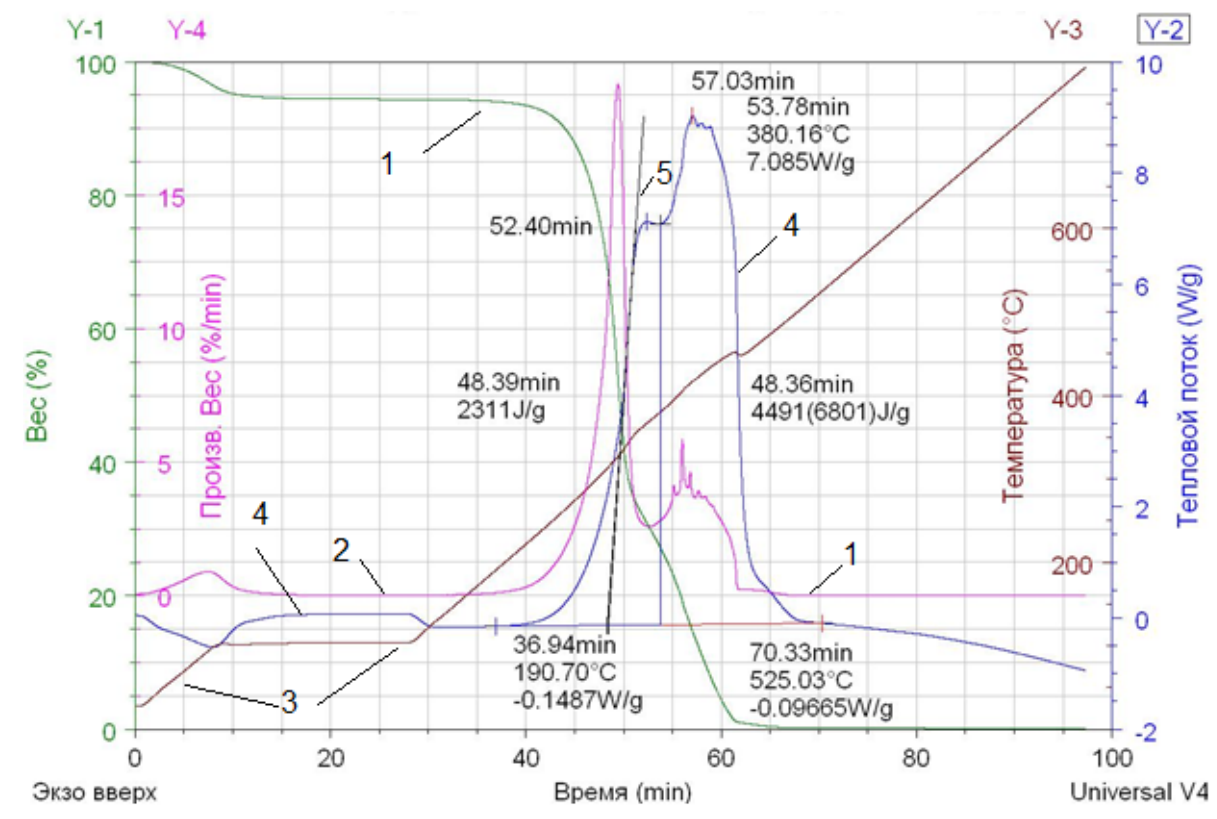

Рисунок 1 - График процесса разложения образца древесной необработанной биомассы. 
Затем, переходя к кривой (4), заметно, что изначально от печи шёл стабильный тепловой поток к образцу, но после выхода почти всех летучих наблюдается небольшая полочка на 52й минуте эксперимента, затем вновь повышение теплового потока. Это и есть момент начала экзотермической реакции в процессе нагрева образца, когда внешний тепловой поток от печи к образцу останавливается, и биомасса начинает испускать собственный тепловой поток. Величина теплового потока определяется из площади под синей кривой, с помощью программного обеспечения. Так же с помощью программы Universal Analisys 2000 были найдены другие значения, которые возможно получить в ходе обработки экспериментальных графиков. Полученные данные сведены в таблицу 1.

Обсуждение полученных результатов и сопоставление их с ранее известными

Обработка результатов заключалась в вычислении таких величин как:

- зольность на сухое состояние (daf), \%, с помощью которой можно было вычислить массовую потерю при торрефикации, \% .

- количество выделившихся летучих веществ, г;

- количество твёрдого остатка, г;

- количество суммарной выделяемой теплоты при окислении, отнесённое к начальной массе образца Q.о.общ., Дж/г;

- количество выделяемой теплоты при окислении летучих вещ-в, отнесённое к начальной массе образца Q.о.лет., Дж/г;

- количество выделяемой теплоты при окислении твёрдого остатка, отнесённое к начальной массе образца Q.о.тв.ост., Дж/г;

- количество суммарной выделяемой теплоты при окислении, отнесённое к потере массы образца (daf) Q.1.общ., Дж/г;

- количество выделяемой теплоты при окислении летучих вещ-в, отнесённое к потере массы образца (daf) Q.1.лет., Дж/г;

- количество выделяемой теплоты при окислении твёрдого остатка, отнесённое к потере массы образца (daf) Q.1.тв.ост., Дж/г;

- количество выделяемой теплоты при окислении летучих вещ-в, отнесённое к массе летучих (daf) - Q.1.удел.теплота горения лет., Дж/г;

- количество выделяемой теплоты при окислении твёрдого остатка, отнесённое к массе твёрдого остатка (daf) Q.1.удел.теплота горения тв.ост, Дж/г.

Где последние две величины по сути являются удельной теплотой сгорания летучих и твёрдого остатка.

Необработанной древесной пеллеты:

Q.1.удел.теплота горения лет. +Q.1.удел.теплота горения тв.ост=

$$
=3238,14+15683,68=18921,82 \frac{\text { Дж }}{г \mathrm{p}}=18,9 \frac{\mathrm{MДж}}{\mathrm{\kappa}}
$$

Торрефицированной пеллеты №1:

Q.1.удел.теплота горения лет.+Q.1.удел.теплота горения тв.ост.=

$$
=4806,33+16172,88=20979,21 \frac{\text { Дж }}{\Gamma \mathrm{p}}=20,9 \frac{\mathrm{MДж}}{\mathrm{\kappa}}
$$


Торрефицированной пеллеты №2:

Q.1.удел.теплота горения лет.+Q.1.удел.теплота горения тв.ост.=

$$
=5520,31+16188,82=21709,13 \frac{\text { Дж }}{г \mathrm{p}}=21,7 \frac{\mathrm{MДж}}{\mathrm{\kappa}}
$$

Торрефицированной пеллеты №3:

Q.1.удел.теплота горения лет.+Q.1.удел.теплота горения тв.ост.=

$$
=8395,32+15428,99=23824,31 \frac{\text { Дж }}{г p}=23,8 \frac{\mathrm{MДж}}{\mathrm{кг}}
$$

Таблица 1 - Данные обработки графиков процесса разложения образцов древесной

\begin{tabular}{|c|c|c|c|c|}
\hline & $\begin{array}{l}\text { Сырая пел- } \\
\text { лета }\end{array}$ & $\begin{array}{l}\text { Торрифи- } \\
\text { кат } 1\end{array}$ & $\begin{array}{l}\text { Торрифи- } \\
\text { кат } 2\end{array}$ & $\begin{array}{l}\text { Торрифи- } \\
\text { кат } 3\end{array}$ \\
\hline Исходная масса образца, г & 45,012 & 30,847 & 14,971 & 20,124 \\
\hline $\begin{array}{l}\text { Зольность в конце кривой потери } \\
\text { массы, \% }\end{array}$ & 0,2312 & 0,5855 & 0,2797 & 0,5824 \\
\hline $\begin{array}{l}\text { Точка на кривой потери массы в } \\
\text { начале процесса (без влажно- } \\
\text { сти), доли }\end{array}$ & 0,9404 & 0,978 & 0,9734 & 0,9743 \\
\hline $\begin{array}{l}\text { зольность на сухое состояние } \\
\text { (daf), \%, }\end{array}$ & 0,2459 & 0,5987 & 0,2873 & 0,5978 \\
\hline $\begin{array}{l}\text { Массовая потеря при торрефи- } \\
\text { кации, \% }\end{array}$ & & 58,93 & 14,44 & 58,87 \\
\hline $\begin{array}{l}\text { Исходная органическая масса } \\
\text { (на daf), доли }\end{array}$ & 42,224 & 29,986 & 19,384 & 19,489 \\
\hline $\begin{array}{l}\text { Середина потери массы на кри- } \\
\text { вой графика (на daf), доли }\end{array}$ & 0,289 & 0,471 & 0,387 & 0,532 \\
\hline $\begin{array}{l}\text { Середина потери массы на кри- } \\
\text { вой графика (на daf), г }\end{array}$ & 12,195 & 14,135 & 7,489 & 10,368 \\
\hline $\begin{array}{l}\text { Количество выделившихся лету- } \\
\text { чих веществ, г }\end{array}$ & 30,134 & 16,034 & 11,942 & 9,239 \\
\hline Количество твердого остатка, г & 12,091 & 13,954 & 7,442 & 10,250 \\
\hline Q.о.общ., Дж/г; & 6380 & 9814 & 9334 & 11743 \\
\hline Q.о.лет., Дж/г; & 2168 & 2498 & 3301 & 3854 \\
\hline Q.о.тв.ост., Дж/г; & 4212 & 7316 & 6033 & 7858 \\
\hline Q.1.общ., Дж/г; & 6801 & 10096 & 9617 & 12094 \\
\hline Q.1.лет., Дж/г; & 2311 & 2570 & 3401 & 3980 \\
\hline Q.1.тв. ост., Дж/г; & 4491 & 7526 & 6215 & 8115 \\
\hline $\begin{array}{l}\text { Q.1.удел.теплота горения тв. } \\
\text { ост., Дж/г; }\end{array}$ & 15683,68 & 16172,88 & 16188,82 & 15428,99 \\
\hline $\begin{array}{l}\text { Q.1.удел.теплота горения лет., } \\
\text { Дж/г; }\end{array}$ & 3238,14 & 4806,33 & 5520,34 & 8395,32 \\
\hline
\end{tabular}
биомассы 
Исходя из таблицы 1 , при сложении удельной теплоты сгорания твёрдого остатка и летучих, получаем интервал низшей теплоты сгорания торрефицированных пеллет от 21 до 24 МДж/кг, что согласуется с данными ранее полученными другими авторами [5,7]. Также, это говорит о целесообразности использования торрефицированных пеллет в качестве альтернативы или совместно с другими твёрдыми топливами, так как низшая теплота сгорания торфа - 23 МДж/кг, бурого угля - 28 МДж/кг [6].

\section{Заключение}

По результатам расчетов можно сделать вывод, что торрефикация пеллет целесообразна. В случае использования реактора торрефикации в режиме, когда в летний период вся тепловая энергия используется на производство торрефицированных пеллет, а в зимний - на собственные нужды позволяет снизить срок окупаемости в 1,23 раза.

Учитывая опыт, изложенный в источнике [7] нужно отметить, что производство торрефицированного топлива тем выгоднее, чем дальше находится потребитель от места производства. Поскольку торрефикат не подвержен воздействию окружающей среды, как обычные пеллеты, а значит не требует дополнительных мер топливо приготовления перед использованием. В частности, как отмечает $[7,8]$ пеллеты, прошедшие торрефикацию, обладают в два раза более низким пределом гигроскопичности по сравнению с необработанными пеллетами. Стоит отметить, что даже при условии длительного хранения основные потребительские характеристики торрефиката остаются неизменными, что в свою очередь позволяет создавать резервные запасы топлива, тем самым обеспечивая энергонезависимость конечного потребителя такого биотоплива.

\section{СПИСОК ЛИТЕРАТУРЫ}

[1]. Basu P. Biomass Gasification, Pyrolysis, and Torrefaction. Practical Design and Theory, 2nd ed. San Diego, CA: Acad. Press, 2013.

[2]. Фомина О. А. Анализ теплотворной способности различных видов топлива и способы ее повышения. Актуальные вопросы науки и хозяйства: новые вызовы и решения. Сб. Мат. LIV Студенческой научно-практической конференции. 2020. C. $169-179$.

[3]. Риполь-Сарагоси Т. Л. Кууск А. Б., Возобновляемые и нетрадиционные источники энергии. Учебно-методическое пособие. Ростов н/Д., Рост. гос. ун-т. путей сообщения, 2019. 122 с

[4]. Шегельман И. Р., Васильев А. С. Зарубежный опыт торрефикации биомассы. Наука и бизнес: пути развития. 2013. № 6 (24). С. 42-44.

[5]. Зайченко В. М. Размышления о концепции развития энергетики. Водородные энергетические технологии. Материалы семинара лаборатории ВЭТ ОИВТ РАН: сборник научных трудов. Редколлегия: Д.О. Дуников (отв. ред.) [и др.]. Москва, 2017. С. 31-38.

[6]. Основы теории горения: Учеб. пособие по курсу "Основы теории горения" для студентов, обучающихся по направлению "Теплоэнергетика" / Л. Т. Пашков; М-во образования Рос. Федерации. Гос. образоват. учреждение высш. проф. образования Моск. энергет. ин-т (Техн. ун-т).М., Изд-во МЭИ, 2002. 135 с.

[7]. Любов В. К., Попова Е. И., Шкаева Н. В. и др. Исследование процесса торрефикации древесины. Вестник Череповецкого государственного университета. 2017. № 3 (78). C. $38-45$.

[8]. TA Instruments SDT Q600 (Eng), www.tainst.com; 
[9]. Совмещённый ДСК-ТГА Q600. Руководство пользователя. Intertech Corporation, Москва 2003 г.

[10]. Зайченко В. М., Сычев Г. А. Шевченко А. Л. Использование тепла экзотермических реакций для повышения производительности установки по торрефикации биомассы Экологическая, промышленная и энергетическая безопасность - 2018. Сборник статей по материалам международной научно-практической конференции. под ред. Л. И. Лукиной, Н. А. Бежина, Н. В. Ляминой. 2018. C. $413-416$.

Геллер Юлия Александровна - канд. техн. наук, доцент кафедры Теоретических основ теплотехники, Национальный исследовательский университет «МЭИ» (Российская Федерация, 111250, Москва, Красноказарменная ул., д. 14)

Ходяшов Евгений Олегович - аспирант кафедры «Энергоресурсоэффективные технологии, промышленная экология и безопасность» Российского государственного университета им. А. Н. Косыгина (Технологии. Дизайн. Искусство) (Российская Федерация, 119071, Москва, Малая Калужская ул., д. 1). 


\title{
Changes in the heat of combustion of wood pellets depending on the degree of their torrefaction
}

\author{
Yu. A. Geller ${ }^{1, *}$, E. O. Khodyashov ${ }^{2}$ \\ ${ }^{1}$ National Research University Moscow Power Engineering Institute \\ ${ }^{2}$ The Kosygin State University of Russia, Moscow, Russia
}

\begin{abstract}
To improve the physicochemical properties of wood pellets, for example, to increase the bulk density, increase the heat of combustion, reduce hygroscopicity, torrefaction is used - a process of slow heating (no more than $50{ }^{\circ} \mathrm{C} / \mathrm{min}$ ) of wood in an inert environment at temperatures up to $300{ }^{\circ} \mathrm{C}$.

The paper compares the characteristics of torrefied and non-heat-treated wood pellets. The results of an experiment on the loss of mass of the sample, the release of volatiles, and the change in the temperature of the sample during the decomposition of a sample of woody biomass are presented. The experiment was carried out on a SDT Q600 thermal analyzer with the Universal Analisys 2000 software.

During the experiment, the pellets were first heated to $103{ }^{\circ} \mathrm{C}$ for 15 minutes, which was accompanied by the removal of moisture, then with heating to $800^{\circ} \mathrm{C}$, thermal decomposition of the sample took place with the release of volatile organic substances. As a result of data processing, the values of the calorific value of untreated $(\approx 19 \mathrm{MJ} / \mathrm{kg}$ ) and (from 21 to $24 \mathrm{MJ} / \mathrm{kg}$ ) torrefied pellets were obtained.
\end{abstract}

\section{Keywords}

Wood pellet torrefaction, calorific value, renewable hydrocarbon resources

\section{REFERENCES}

[1]. Basu P. Biomass Gasification, Pyrolysis, and Torrefacation. Practical Design and Theory, 2nd ed. San Diego, CA: Acad. Press, 2013.

[2]. Fomina O.A. Analiz teplotvornoj sposobnosti razlichnyh vidov topliva i sposoby ee povyshenija [Analysis of the calorific value of various types of fuel and ways to increase it]// V sb.: Aktual"nye voprosy nauki i hozjajstva: novye vyzovy i reshenija. Sb. Mat. LIV Studencheskoj nauchno-prakticheskoj konferencii. [In the collection: Actual issues of science and economy: new challenges and solutions. Collection of materials of the LIV Student scientific-practical conference.] 2020. pp. 169-179. (In Russ.)

[3]. Ripol'-Saragosi T.L. Kuusk A.B., Vozobnovljaemye i netradicionnye istochniki jenergii [Renewable and unconventional energy sources]. Uchebno-metodicheskoe posobie. Rostov n/D: Rost. gos. un-t. putej soobshhenija Publ. [Study guide. Rostov n/D: Growth. state un-t. railways] 2019. 122 p (In Russ.)

[4]. Shegel'man I.R., Vasil'ev A.S. Zarubezhnyj opyt torrefikacii biomassy [Foreign experience of biomass torrefaction] // Nauka i biznes: puti razvitija [Science and business: 
ways of development]. 2013. № 6 (24). pp. 4244. (In Russ.)

[5]. Zajchenko V.M. Razmyshlenija o koncepcii razvitija jenergetiki [Reflections on the concept of energy development]//V sb.: Vodorodnye jenergeticheskie tehnologii. Materialy seminara laboratorii VJeT OIVT RAN: sbornik nauchnyh trudov. [In the collection: Hydrogen energy technologies. Materials of the seminar of the laboratory of VET JIHT RAS: collection of scientific papers. Moscow, 2017. S. 31-38. (In Russ.)

[6]. Osnovy teorii gorenija: Uch.[Fundamentals of the theory of combustion: Textbook. allowance] Pos. po kursu "Osnovy teorii gorenija" / L.T. Pashkov. - Moscow: Izdvo MPEI, 2002. - 135 p. (In Russ.)

[7]. Ljubov V. K., Popova E. I. Issledovanie processa torrefikacii drevesiny [Investigation of the process of torrefaction of wood] // Ljubov V. K., Popova E.I., Shkaeva N.V., Bolotova K.S., Solnyshkova L.M. Vestnik Cherepoveckogo gosudarstvennogo universiteta [Bulletin of the Cherepovets State University.]. 2017. № 3 (78). S. 38-45. (In Russ.)

[8]. TA Instruments SDT Q600 (Eng), www.tainst.com ;

[9]. Sovmeshhjonnyj DSK-TGA Q600. Rukovodstvo pol'zovatelja. - Intertech Corporation, Moscow 2003.; (In Russ.)

[10]. Zajchenko V.M., Sychev G.A. Ispol'zovanie tepla jekzotermicheskih reakcij dlja povyshenija proizvoditel'nosti ustanovki po torrefikacii biomassy [Using the heat of exothermic reactions to increase the productivity of the biomass torrefaction plant // Zajchenko V.M., Sychev G.A., Shevchenko A.L. V sbornike: Jekologicheskaja, promyshlennaja i jenergeticheskaja bezopasnost' - 2018. sbornik statej po materialam mezhdunarodnoj nauchnoprakticheskoj konferencii. [Environmental, industrial and energy security - 2018. Collection of articles based on the materials of the international scientific and practical conference] 2018. pp. 413-416. (In Russ.).

Geller Yu. A. - Cand. Sc. (Eng.), Assoc. Professor, Department of Theoretical Foundations of Heat Engineering, National Research University Moscow Power Engineering Institute (Krasnokazarmennaya 14, Moscow, 111250 Russian Federation)

Khodyashov E. O. - postgraduate student, Department of Energy and Resource Efficient Technologies, Industrial Ecology and Safety, The Kosygin State University of Russia (Malaya Kaluzhskaya ul. 1, Moscow, 119071 Russian Federation).

\section{Просьба ссылаться на эту статью следующим образом:}

Изменение теплоты сгорания древесных пеллет в зависимости от степени их торрефикации / Ю. А. Геллер, Е. О. Ходяшов// Промышленные процессы и технологии. 2021. № 2. C. $81-90$.

DOI: $10.37816 / 2713-0789-2021-1-2-81-90$

\section{Please cite this article as:}

Geller Yu. A., Khodyashov E. O. Changes in the heat of combustion of wood pellets depending on the degree of their torrefaction. Industrial processes ang Technologies, 2021, no. 2 , pp. $81-90$

DOI: $10.37816 / 2713-0789-2021-1-2-81-90$ 